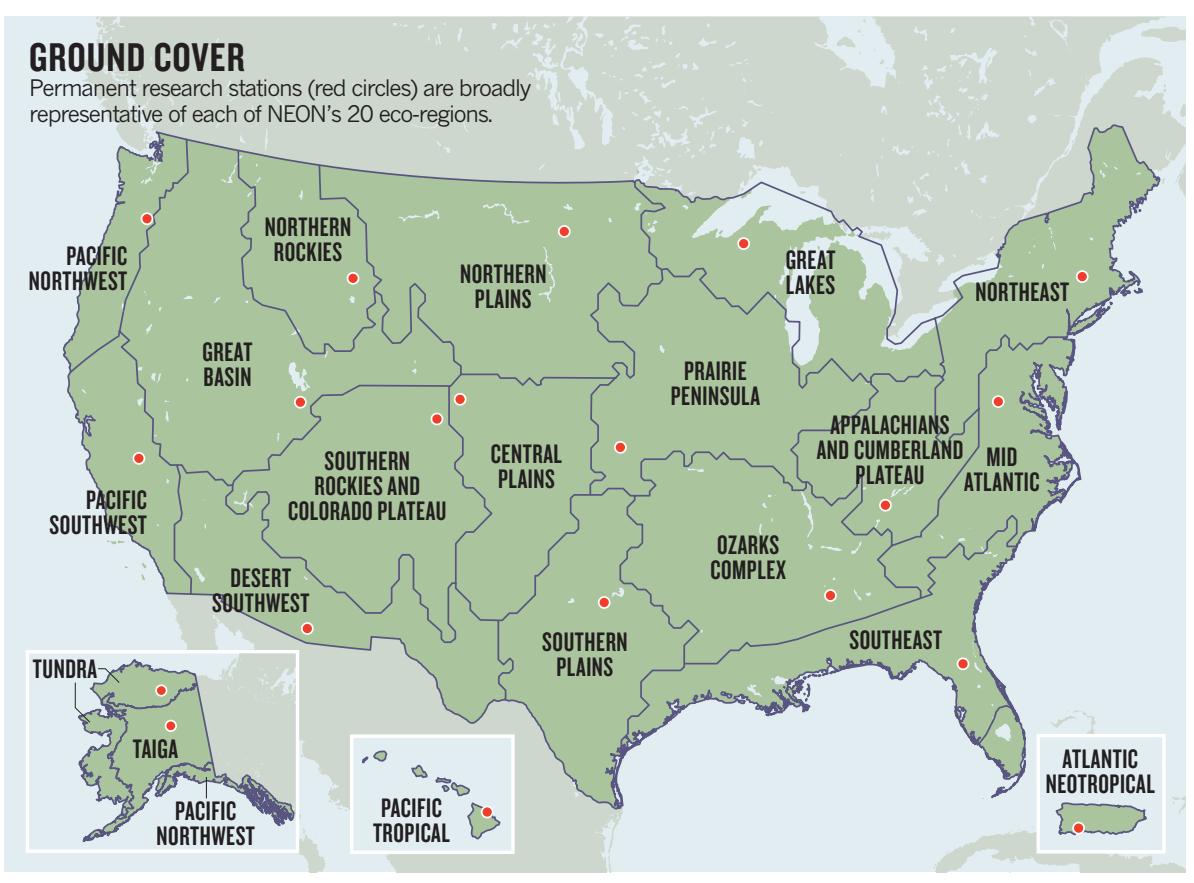

ECOLOGY

\title{
US launches eco-network
}

\section{Ambitious project to systematically monitor the environment on a continental scale is finally ready to break ground.}

\section{BY JEFF TOLLEFSON}

$\mathrm{R}$ eady or not, the era of big data is coming to ecology. After years of discussion and debate, the United States is moving forward with an environmental monitoring network that promises to help transform a traditionally small-scale, local science into a continental-scale group enterprise.

The National Ecological Observatory Network (NEON) will consist of 20 'core' observatories representing distinct eco-regions throughout the United States (see map). These will be bolstered by temporary stations that can be relocated wherever data need to be collected. The sites will house equipment and host visiting researchers, while gathering a range of environmental data over at least three decades.

The result will be a vast database that scientists can mine to tackle broad questions such as how global warming, pollution and landuse change are affecting ecosystems across the country. "NEON is really about trying to understand the biology of the entire continent rather than the biology of a specific place," says David Schimel, the project's chief science officer, based in Boulder, Colorado.

Conceived more than a decade ago, NEON has already spent just over US\$80 million planning the network and developing instruments, and has a staff of about 140 , including some 60 scientists and engineers. But the project, which is run by an independent body - NEON, Inc. - didn't clear its final hurdle until 28 July, when the National Science Foundation (NSF) awarded it \$434 mil-

lion over the next decade, with $\$ 12.5$ million to be spent in the current fiscal year.

The money could jump-start site preparation and construction as early as this year. Schimel says that NEON expects to begin work near its home base in Colorado and in the northeast and to expand from there. The first data, from sensors placed on towers, submerged in streams and buried in soils, should come next year - a trickle that project members hope will become a torrent by 2016 , when the project will be fully operational.

"It's a huge step forward," says Sandy Andelman, an ecologist who heads a network of tropical ecology sites through Conservation International in Arlington, Virginia. But, she cautions, NEON will create a massive new data set that few environmental scientists know how to use today. "Being able to manage and process and make sense of those data is going to be a huge challenge," Andelman says.

Once the entire network is up and running, some 15,000 sensors will work in concert with scientists on the ground to supply roughly 500 distinct categories of data ranging from basic weather readings to concentrations of ozone in the air and nitrogen in the soils, leaves and streams. Scientists will collect tens of thousands of samples, including soil, water, plants and small mammals. At the same time, aerial surveys will analyse broader land-use trends as well as details such as leaf chemistry and carbon stocks, and satellite data will expand coverage over the entire continent.

NEON's draft scientific plan, released on 4 August, identifies climate, land use and invasive species as drivers of ecosystem change that can be studied through their impact on biodiversity, biogeochemical and hydrological cycles and the spread of infectious diseases. By gathering data over large territories and long periods of time, NEON will aim to give scientists the statistical power they need to tease out subtle trends in a shifting ecological balance. For this reason, rather than focusing on regional investigations, the research stations are mainly designed to gather data in a uniform manner that can be used in larger network studies.

"The big intellectual hurdle was the transition from a series of largely regional sites to an integrated system," says James Collins, an ecologist at Arizona State University in Tempe, who as head of the biological sciences directorate at the NSF during 2005-09 helped to mould the proposal into its current form.

Over the years the project has battled against scepticism. Early on, Steven Wofsy, an atmospheric chemist at Harvard University in Cambridge, Massachusetts, and a pioneer of carbon studies at the Harvard Forest ecological research centre, feared that NEON would generate more data than value. Today he gives NEON credit for putting high-profile critics including himself - on its scientific advisory board to address any problems head on.

Wofsy remains sceptical of big science projects that promise to open up a new field with lots of data that scientists haven't necessarily said they want. But he commends NEON for developing a plan to tackle scientific questions that will play out over decades.

"If these guys are successful, they will have the goods on some really big ecological questions," Wofsy says. "Scientists who are interested in addressing those problems will have to make the effort to learn how to use those data." - SEE EDITORIALP.I25 